ISSN: 2224-0616

Int. J . Agril. Res. Innov. \& Tech. 6 (1): 1-7, J une, 2016

Available online at http:// www.ijarit.webs.com

\title{
APPLYING SOCIAL NETWORK ANALYSIS, CENTRALITY MEASURES IN IDENTIFICATION OF CLIMATE CHANGE ADAPTATION OPINION LEADERS
}

\section{Othieno J oseph ${ }^{*}$, Mugivane I Fred ${ }^{2}$, Nyaga Philip ${ }^{3}$, Ogara William ${ }^{4}$ and Muchemi Gerald ${ }^{5}$}

Received 10 February 2016, Revised 17 May 2016, Accepted 21 June 2016, Published online 30 June 2016

\begin{abstract}
Climate change is negatively affecting livelihoods dependent on rain fed agriculture in Kenya. Adaptation through adoption of appropriate agricultural technologies is necessary. Communication plays a critical role in dissemination of climate change information and adaptation. The study applied social network analysis (SNA) using NodeXL computer programme to generate socio-grams that showed patterns of information flow from which important network and individual characteristic of the opinion leaders were described. This study shows that SNA is applicable in climate change communication to identify opinion leaders by mapping out information flow patterns and using measures of centrality.
\end{abstract}

Keywords: Social Network Analysis, Climate Change, Information Flow

${ }^{1 \& 2}$ Department of Agricultural Economics, University of Nairobi, Kenya

${ }^{3}$ Faculty of Veterinary Medicine, University of Nairobi, Kenya

${ }^{4 \& 5}$ Department of Veterinary Public Health, Pharmacology and Toxicology, University of Nairobi, Kenya

*Corresponding author's email: jothieno43@yahoo.com (Dr. Othieno Joseph)

\section{Introduction}

Agricultural production remains the main source of livelihoods for rural communities in Africa (Nhemachena and Hassan, 2007; Quiggin et al., 2010). According to Ojwang' et al. (2010), 57 percent of these people live below the poverty line of less than 1 dollar per day, and largely rely on climate-sensitive agricultural activities. Globalization, changing consumption patterns, climate change and emerging diseases are shaping development in agricultural production (ILRI, 2008). Although man has been adapting to other changes in environment; for example, economic development and globalization, climate change presents the greatest challenge to human endeavors, key among them being agricultural production (Smith et al., 2001; Global Humanitarian Forum, 2009).

Climate change directly affects agricultural production in developing countries due to the sector's sensitivity to the risks and Africa's socioeconomic, demographic and policy trends that limit their capacity to adapt to climate change (Parry et al., 1999; Fankhauser, 1995). In these countries climate change is a silent enemy that will affect high risk and stressed agro-ecosystems as its effects are not immediately visible (Kgakatsi, 2006). Kenya is among countries that are ready experiencing effects of climate change since rain-fed agriculture is the largest contributor to the GDP (GoK, 2010).

Adaptation is an important approach in coping with the climate change for smallholder farmers to increase their production through adoption of appropriate techniques. Adoption begins with information sharing among potential users (Gailhard, 2012). This process occurs through interpersonal communication channels, which exist in the social system. Communication of the agricultural adaptive measures between scientists, extension agents and farmers play a crucial role in adaptation process. Smallholder farmers have been adapting to changing climate since time immemorial (McDowell and Hess, 2012). Social systems have characteristics that sustain or hinder adaptation and adoption process. Nonetheless strengthening of the adaptive capacities is essential for future sustainable and equitable development particularly for livelihoods sensitive to climate change (Osbahrh et al., 2010).

The growing of drought resistant, drought avoiding (early maturing) crop varieties, and irrigation are some of adaptation techniques chosen by the farming communities in Kenya to cope with climate change. The adoption of these techniques occurs within a social network and is initiated by awareness of the existence of the technique through information exchange. The actors in the information exchange process play different roles, which determine the flow of such information and resultant communication pattern; key among these actors are opinion leaders. An understanding of how this information flows through a social system is important in agricultural extension. 
Social networks have an impact on the current demand driven extension approaches that accelerate adoption of innovative techniques by smallholder farmers in developing countries (IFPRI, 2010). In agricultural extension links exist among, extension agents and farmers that either promote (or hinder) the adoption of new technologies; (Bandiera and Rasul, 2006). Farmers in social networks learn how to cultivate new crops from the choices of other farmers cultivating the same crop (Foster and Rosenzweig, 2010; Conley and Udry, 2010).

Opinion leaders play a critical role in this information flow since it is human behavior to seek advice from others in a social setting (Shahara et al., 2011). The concept of opinion leaders was studied by Lazarsfeld et al. (1948) and led to the development of the Two-Step Flow theory of Communication. According to the theory messages from the mass media do not flow directly to target audiences but goes through a mediation process where another group of people digested it and disseminated it to the masses. This mediating group exerts influence on the decision of group members (Rogers and Cartano, 1962). Opinion leaders possess certain characteristics that endear them to be influential in the decision making process and behavior of their followers.

Several methods have been used to identify opinion leaders among them observation, grading by key players, social interpersonal relationship measure and self-identification (Roger, 2003; Sharara et al., 2011). These methods are subjective largely hence the need for a more objective method of identifying opinion leaders.

There is however limited literature on the study of information flow in agricultural field using a methodology that integrates communication, statistics and graph theory (Freeman, 2004). Such a methodology will enhance the understanding of how information flows through a social system.

Social Network Analysis (SNA) is a relatively new methodology that has gained currency due to its ability to combine graph theory, statistics and computer programmes to produce visual sociograms and indices that assign values to relationships in a network. This study used social network analysis (SNA) through NodeXL computer programme to generate socio-grams that showed the patterns of information flow. Centrality measures were used to identify the opinion leaders; this was later corroborated by follow-up telephone interviews to ascertain their characteristics.

The aim of this study is therefore to use social network analysis of climate change adaptation information flows in an agricultural setting to identify opinion leaders.

\section{Study site}

Sakai Sub-location is approximately $24.5 \mathrm{Km}^{2}$, and is composed of five villages namely: Kathamba, Muiu, Kiteani, Linga and Nthongoni with a population of 4,866 and about 520 households. Sakai sub-location is located in Waia location, Kisau division and Mbooni East District, Makueni County in Kenya. Famers in this sublocation, who relied on rain fed agriculture, have increasingly been threatened by adverse effects of climate change and they have made certain choices to mitigate these challenges that could be studied.

\section{Methodology}

\section{Data collection}

The data was collected from the five villages using self-administered questionnaires, observation and key informant interviews. Recall of names by respondents was used to generate a minimum of one name to a maximum of four names of fellow actors who act as either a source or receiver of information.

Data was collected concurrently in the five villages in Sakai sub-location. To start off the process of data collection; a farmer implementing climate change adaptation agricultural technique(s) was identified by observing their farms and brief interview from where snowball sampling technique was used to identify other subsequent farmers based on information exchange on the agricultural techniques.

\section{Data analysis}

The data was analyzed using NodeXL version 1.0.1.245, SPSS version 18 and STATA version 10. NodeXL was used to do the social network analysis by analyzing the relational data and to generate socio-grams at group and individual levels and socio metric indices.

A total of 164 questionnaires were administered (Muiu village 34, Nthogoni 30, Kiteani 24, Linga 36 and Kathamba 40) administered was analyzed. The study had targeted 220 respondents.

Two measures of centrality namely in-degree and out-degree were used to identify opinion leaders (Momtaz et al., 2011). All the socio-grams generated are directed (direction of information flow is given) two NodeXL layouts of visualization namely Fruchterman-Reingold and Harel- Koren Fast Multiscale were used. Finer visualization was given using Sub-graph socio-grams showing networks at smaller groups levels with emphasis on individuals with higher in-degree and outdegree values. The names are omitted from the 
socio-grams to avoid crowding but sub-graphs for actors are provided as examples.

In the whole network, two self-loops were recorded. This was attributed to data entry errors where four actors shared names and therefore, on plotting the socio-gram, it shows them sharing or getting information from themselves, which is not practically possible.

\section{Results and Discussion}

\section{Network characteristics}

The Sakai sub-location networks are characterized by concentration of central actors that form positions around which subgroups form as well as many peripheral actors (figure 1 whole sub-location and figure $2 \& 3$ individual villages).
Most of the peripheral actors have some form of linkage to central actors. However, unlike the individual village socio-grams (fig. $2 \& 3$ ) this is because of combined socio-grams where peripheral actors are acting as links across villages. These actors when viewed at village level will appear to be weakly linked to the centre when they are actually central actors in their respective villages.

The average out-degree and in-degree of 1.11 shows how all the farmers in the sub-location are linked.

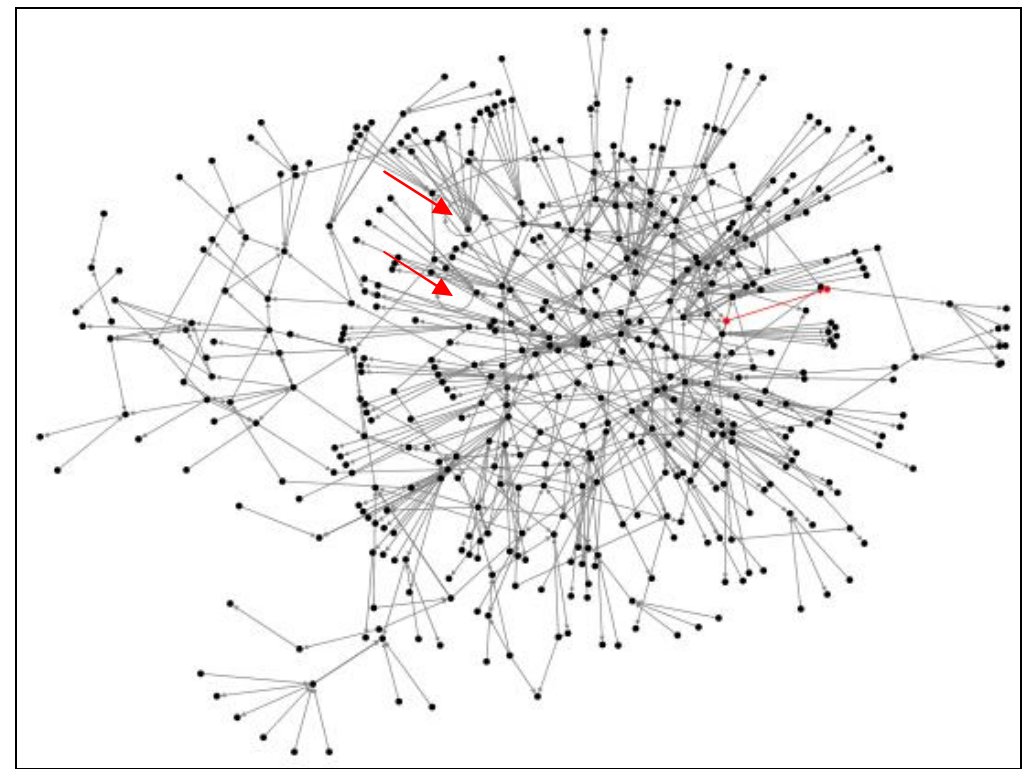

Fig. 1. Sakai sub-location socio-gram Harel-Koren Multiscale format; (notice the two self-loops shown by the arrow)

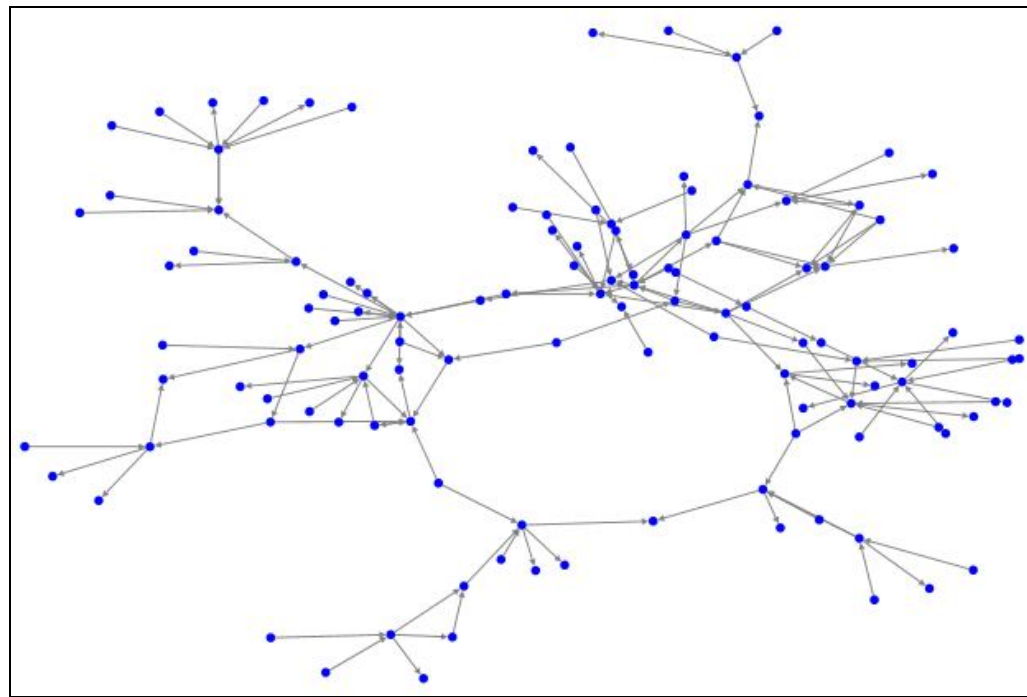

Fig. 2. Muiu village socio-gram (Harel-Koren Fast multiscale format) 
In figure 2, notice the various groups within the weakly linked to other groups through a few sociogram that are strong bonded together but group members.

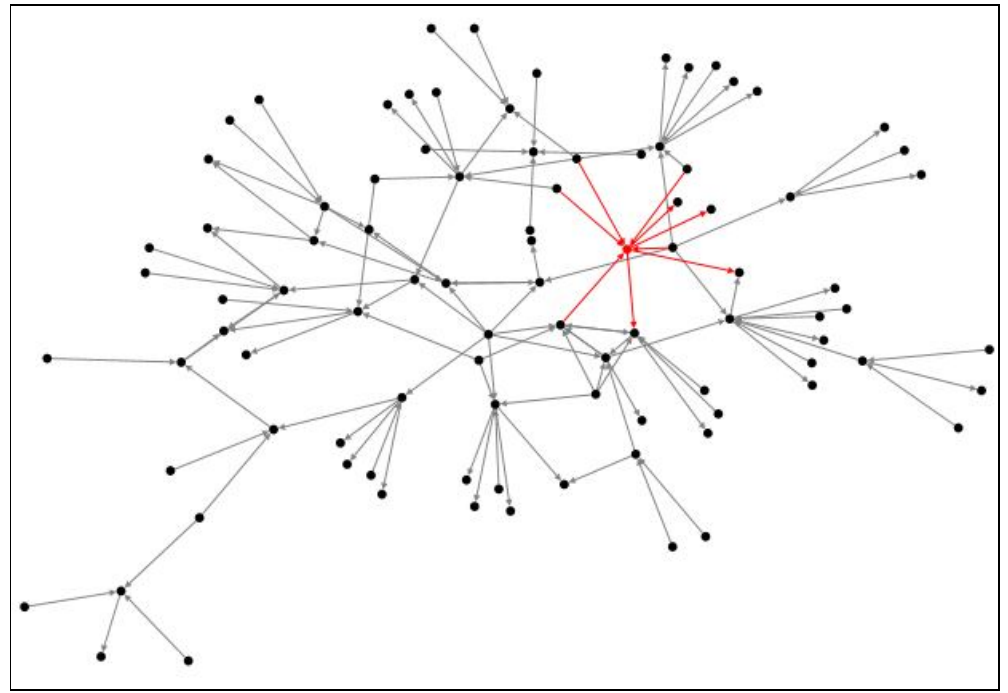

Fig. 3. Kiteani socio-gram (Harel-Koren Fast Multiscale format) showing an actor who is centrally positioned who is core to the group but also acts as a link between this group and other groups

The socio-gram below (fig. 4) shows the relational relations that create opportunities for basis upon which the groups are formed. The engagement. Relatives, neighbours, friends and farmers in Sakai sub-location form groups that social groupings formed the nexus through which feed into the overall network based on certain information was shared.

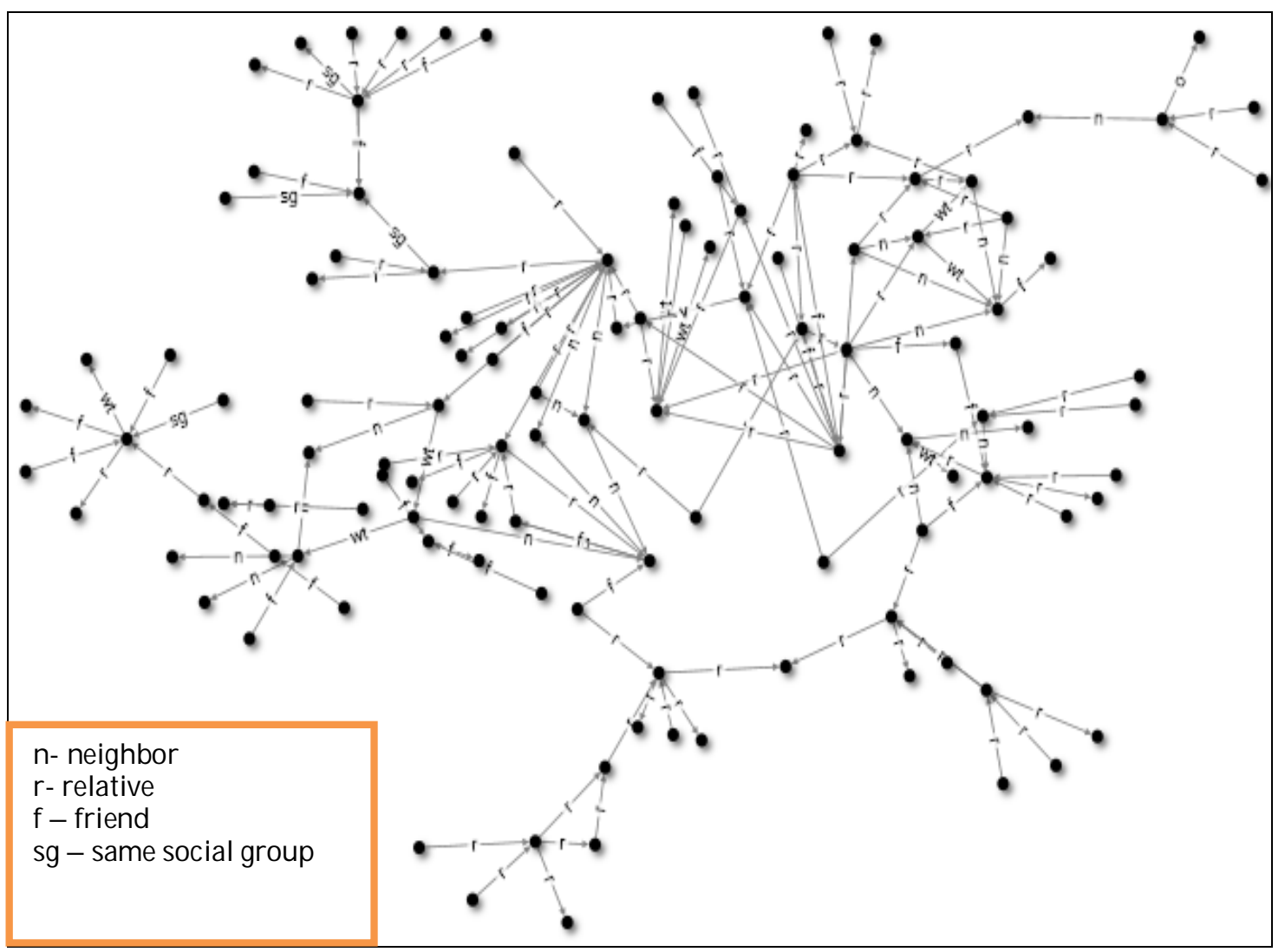

Fig. 4. Socio-gram of Kiteani village showing the how edges develop based on the type of relationship 
The bridging ties and subgroups show clustering in the network which may be built around specific agricultural information, and supported by the relational ties (Fig. 4). The bonding ties in Sakaisub-location are relational ties between family members, friends and relatives and group memberships. These relations explain the existence of strong bonding ties and weak bridging ties in Sakai sub-location. These ties act as pathways for information that exist in one network to a member of another network (Granovetter, 1973).

Bonding ties result in dense network structures with strong and localized trust which can lead to imposition of social norms which have the effect of reducing the diversity and hence resilience of groups (Newman and Dale, 2005) also such networks result in the exclusion of outsiders or those at the periphery of the network (Portes,

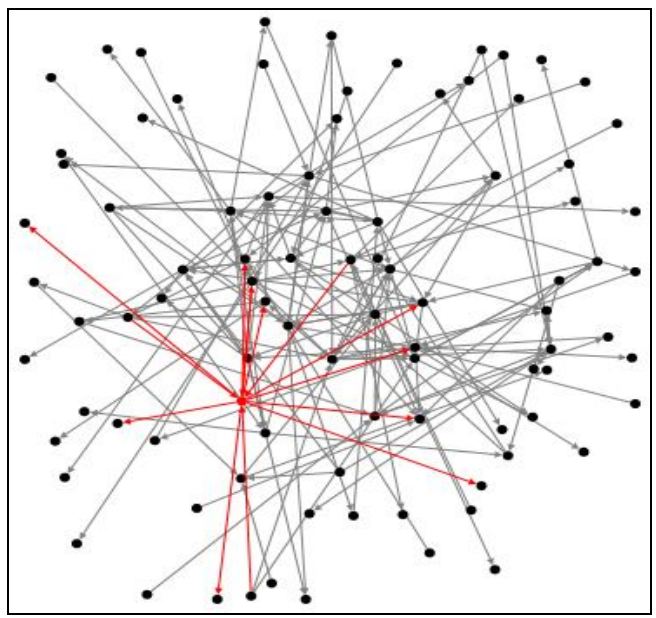

Fig. 5. Kioko in-degree 4 and out-degree 10

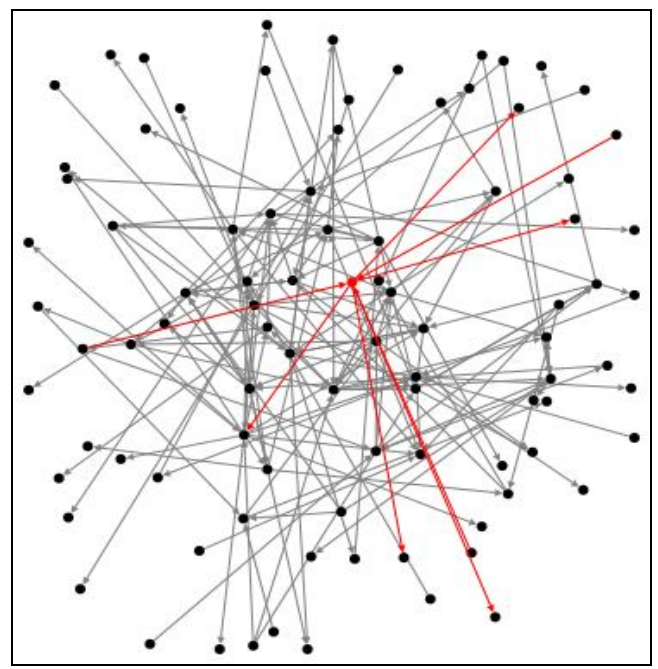

Fig. 7. Wambua in-degree 3 and out-degree 5
1998). While bonding ties may restrict diffusion of information outside a group and result in the development of restricting norms bridging ties enables an actor to access information from other networks (groups) and will assist in overcoming the restrictions imposed by the bonding ties. Tompkins and Adager (2004), Newman and Dale (2005) assert that bridging ties are important in community mobilization.

\section{Identification of opinion leaders}

Two-degree centrality measures were used namely; in-degree and out-degree to identify opinion leaders in the social network. Figures 5, 6, 7 and 8 shows ego networks of the opinion leaders we were able to identify. The in-degree and out-degree indices are derived from the table generated by the NodeXL programme and are given alongside the ego network socio-grams.

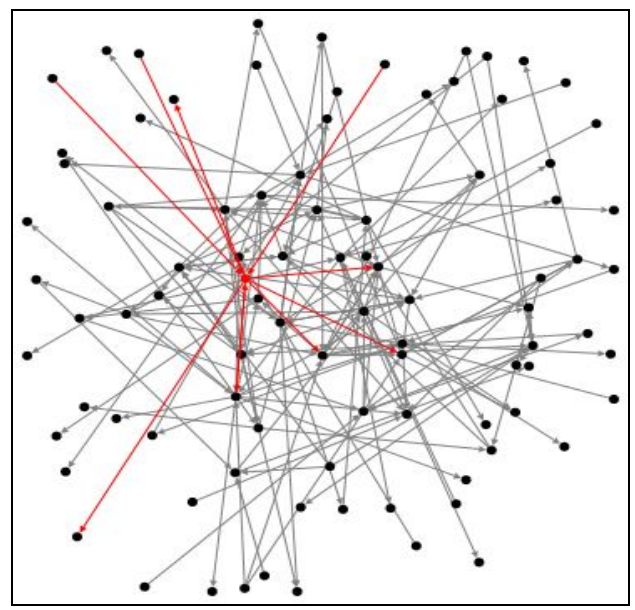

Fig. 6. Munyu in-degree 4 and out-degree 6

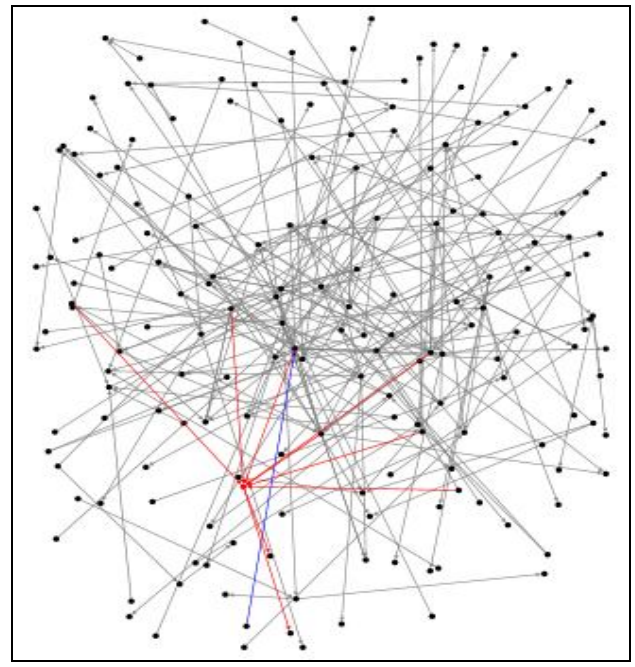

Fig. 8. Musembi In-degree 7 out-degree 2 


\section{Characteristics of opinion leaders}

After identification of opinion leaders using centrality measures namely in-degree and out- degree a follow up telephone interview was done. Five opinion leaders were interviewed for common traits using the check list in Table 1.

Table 1. Checklist for the telephone interview with the opinion leaders

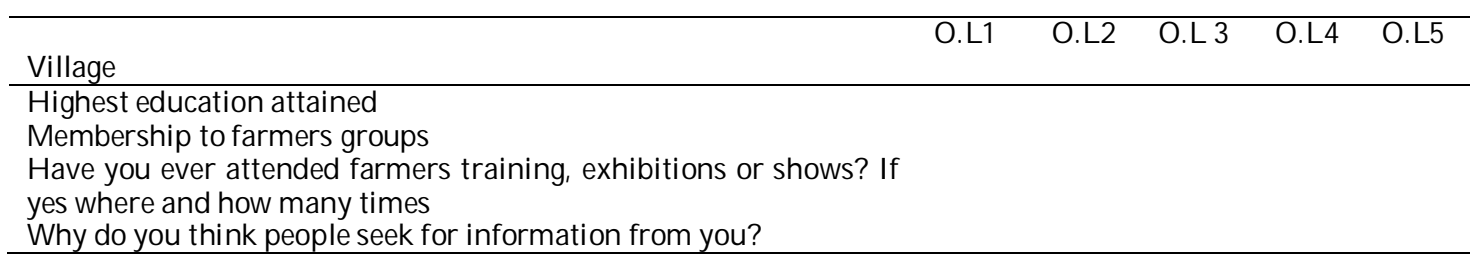

According to the telephone interview; all the four farmers identified as opinion leaders were relatively well educated, were members of local farming groups and had associations with other national farmer groups. They had previously learned modern farming practices from workshops or friends and were implementing other farming practices like green houses and dairy animal production. Their influence on other farmers was thus based on their ability to bond with their local communities and contact with external sources of information. This presents a practical application of the homophily and heterophily principle in enhancing communication and adoption of innovations. The opinion leaders owing to their origin within the local social systems are homophilous but their contact with outside sources makes them heterophilous relative to their local contacts. However, it is this heterophily that endears them to get new information, which they share with their homophilous contacts and subsequently play a crucial role in the diffusion of innovations.

Opinion leaders are people with great exposure to mass media, have contact with change agents, are likeable and trustworthy (Rogers, 2003; Flodgren et al., 2010; Grimshaw et al., 2012). They are able to access information and relay it to their followers in a palatable form. These qualities, which are earned over time through conformity to systems norms and culture, make them local influence agents critical in decisionmaking (Dearing, 2009; Grimshaw et al., 2012).

\section{Conclusion}

The study illustrates the importance of informal social networks in the diffusion of information on climate change adaptation and their utilization in climate change adaptation communication. Every community has these networks which have been formed over time and which can be exploited in agricultural extension as a cost effective strategy. The study shows that SNA can be applied in the study of agricultural communication by identifying opinion leaders and mapping out patterns of information flow through a social system.

\section{References}

Bandiera, O. and Rasul, I. 2006. Social networks and technology adoption in northern Bolivian highlands under a changing climate. Global Environment Change 2012. p.22.

Conley, T.G. and Udry, C. 2010 Social learning through networks: The adoption of new Agricultural technologies in Ghana. American J. Agril. Econ. 83(3): 668-673.

Dearing, J.W. 2009. Applying diffusion of innovation theory to intervention development. Res. Soc. Work. Pract. 19(5): 503-518.

Fankhauser, S. 1995. Valuing Climate Change: The Economies of Greenhouse, London: Earth Watch. 194p.

Freeman, L.C. 2004. The Development of Social Network Analysis: A Study in the Sociology of Science. Empirical Press, Vancover. 30p.

Flodgren, G., Parmelli, E., Doumit, G., Gattellari, M., O'Brian, M., Grimshaw, J . and Eccles, M. 2010. Local opinion leaders: effects on professional practice and health care outcomes. The Cochrane Library doi: 10.1002/ 14651858.CD000125.pub4.Issue 11.

Foster, A.D.W. and Rosenzweig, M.R. 2010 Micro-economics of technology adoption. Ann.l Rev. Econ. 2: 395-424.

Gailhard, U.I. 2012. The influence of communication frequency with social network actors on the continuous innovation adoption: Organic farmers in Germany. 131st EAAE Seminar 'Innovation for Agricultural Competitiveness and Sustainability of Rural Areas', Prague, Czech Republic Sept. 18-19, 2012.

Global Humanitarian Forum. 2009. Human Impact Report: Silent Crisis http:// www.ghfgeneva.org/ Portals/ 0/pdfs/ human impact report.pdf [Accessed on 26 October, 2014]

GoK. 2010. National Climate Change Response Strategy(NCCRS) http:// cdkn.org/wpcontent/uploads/2012/04/NationalClimate-Change-Response-Strategy April2010.pdf accessed on 30th Nov, 2014) 
Granovetter, M. 1973. The strength of weak ties. The American J. Soc. 78(6): 1360-380.

Grimshaw, J., Eccles, M., Lavis, J., Hill, S. and Squires, J. 2012. Knowledge translation of research findings. Implement Sci. 7(1): 50.

IFPRI. 2010. Climate variability and climate change impacts on Kenyan agriculture. https:// www.ifpri.org/ publication/ climatevariability-and-climate-change [accessed on 1st Dec. 2014]

ILRI. 2008. Concepts and practices in agricultural extension in developing countries.

http:/ / ebrary.ifpri.org/ utils/ getfile/ collectio n/p15738coll2/id/ 126803/filename/ 127014. pdf [accessed on 20th Dec. 2014]

Kgakatsi, L. 2006. Climate Change and the DoA: Yesterday, today and tomorrow: Proc. Agricultural Sector in Climate Change Workshop. February 2006, Pretoria, South Africa.

Lazarsfeld, P.F., Berelson, B. and Gaudet. H. 1948. The people's choice: How the voter makes up his mind in a presidential campaign. New York: Duell, Sloan and Pearce. pp. 135-152.

McDowell, J. and Hess, J.J. 2012: Accessing adaptation: multiple stressors on livelihoods in the Bolivian Highlands under a changing climate. Glob. Env. Change 22(2): 342-352.

Momtaz, M., Aghaie, A. and Alizadeh, S. 2011. Identifying opinion leaders for marketing by analyzing online social networks, Int. J . Virtual Comm. Soc. Net. 3(1): 43-59.

Newman, L. and Dale, A. 2005. Network structure, diversity and proactive resilience building: a Response to Tompkins and Adger. Ecology and Society, 10(1): Ecology \& Society 10(1): r2. [online] URL: http:// www.ecologyandsociety.org/vol10/iss 1 /resp2/[accessed on 24th Dec. 2014]

Nhemachena, C. and Hassan, H. 2007. Microlevel analysis of farmers' adaptation to climate change in Southern Africa. IFPRI Discussion paper no. 00714. IFPRI Washington DC. pp. 668-673.

Ojwang', G.O., Agatsiva, J . and Situama, C. 2010. Analysis of climate change and variability risks in the smallholder sector: Case studies of the Laikipia and Narok districts representing major Agro-ecological zones in Kenya.

http:// www.fao.org/ docrep/ 013/i1785e/i178 5e00.pdf [accessed: $11^{\text {st }}$ May, 2014]

Osbahrh, H., Twyman, C., Adger, W.H. and Thomas, D.S.G. 2010. Evaluating successful livelihood adaptations to climate variability and change in Southern Africa. Eco. \& Soc. 15(2): 27.

Parry, M., Rosenzweig, C., Iglesias, A., Fischer, G. and Livermore, M. 1999. Climate change and world food security: A new assessment. Glob. Env. Change 9: S51-S67.

Portes, A. 1998. Social capital: its origins and applications in modern sociology. Ann. Rev. Soc. 24: 1- 24.

Quiggin, J., Adamson, D., Chambers, S. and Schrobback, P. 2010. Climate Change, Uncertainty and Adaptation: The Case of Irrigated Agriculture in the Murray-Darling Basin in Australia. Canada J. Agril. Econ. 58(4): 531-554. DOI: 10.1111/j.17447976.2010.01200.x

Rogers, E.M. 2003. Diffusion of innovations ( $5^{\text {th }}$ ed.). New York: Free Press.

Rogers, E.M. and Cartano, D.G. 1962. Method for Measuring Opinion leadership. The Public Opinion Quart. 26(3): 435-441.

Sharara, H., Getoor, L and Norton, M. 2011. Active surveying: A probabilistic approach foridentifying key opinion leaders. In: Proceedings of the 22nd International J oint Conference on Artificial Intelligence, Barcelona, Catalonia, Spain, 16-22, July 2011.https:// www.aaai.org/ocs/index.php/I J CAI/ IJ CAI11/ paper/ view/3375/3465. [accessed: 20th J un. 2014].

Smith, B., Pilifosova, O., Burton, I., Challenger, B., Huq, S., Klein, R.J.T., Yohe, G., Adger, N., Downing, T., Harvey, E., Kane, S., Parry, M., Skinner, M. and Smith, J. 2001. Adaptation to climate change in the context of sustainable development and equity: Climate Change 2001: Impacts, Adaptation, and Vulnerability. Cambridge Univ. Press. pp. 877-912. 